\title{
Morphological and optical properties of dielectric multilayer structures prepared with distinct precursor concentrations
}

\author{
Venkatesh Yepuri $^{1,2}$, R. S. Dubey ${ }^{1 *}$, Brijesh Kumar $^{2}$ \\ ${ }^{1}$ Department of Nanotechnology, Swarnandhra College of Engineering and Technology, \\ Seetharampuram, Narsapur (A.P.), India \\ ${ }^{2}$ Amity Institute of Nano Science and Technology, Amity University, Gurgaon, (Haryana), India \\ rag_pcw@yahoo.co.in
}

DOI 10.17586/2220-8054-2019-10-3-355-360

For optical filters, $\mathrm{TiO}_{2}$ and $\mathrm{SiO}_{2}$ films are better choices due to their large refractive index contrast. In spite of the various available techniques, the sol-gel spin coating method is one of the easiest and inexpensive technique. Here, we report the experimental studies of $\left(\mathrm{TiO}_{2} / \mathrm{SiO}_{2}\right)_{2.5}$ bilayer-based structures prepared with two distinct precursor concentrations. FTIR analysis showed the characteristic vibration peaks of the Ti-O-Ti and Si-O-Si bonds. XRD measurements of both the samples based on the low and high-precursor concentrations, revealed the dominant peaks of $\mathrm{TiO}_{2}$-anatase phase. FESEM study endorsed the increased thicknesses of the individual layers due to enhanced precursor concentrations. Both samples evidenced for the reflection/stop bands with $100 \%$ reflectivity. Furthermore, multilayer structure of $\left(\mathrm{TiO}_{2} / \mathrm{SiO}_{2}\right)_{2.5}$ bilayers showed the corresponding shift of the reflection band from the visible-infrared wavelength region in accordance with the low-high precursor concentration. This shifting of the reflection band is attributed to the increased thicknesses of the films which is due to the enhanced grains size as confirmed by the AFM studies.

Keywords: reflectors, multilayers structures, cross-section SEM morphology, precursor concentration.

Received: 4 February 2019

Revised: 18 April 2019

\section{Introduction}

Dielectric multilayer structures are the choice of passive components in optoelectronic and photonic devices. These passive components are promising for the manipulation of light in an efficient manner. Multilayer structures, composed of two distinct materials, have been investigated as the stop band filters in the design and fabrication of solar cells, waveguide, micro cavities etc. [1-6]. Such multilayer structures can be prepared by either of the techniques, such as chemical vapor deposition, electrodeposition, sputtering and sol-gel spin coating process [7-9]. Among aforementioned techniques, the sol-gel spin coating process is inexpensive and has advantages to tune the film properties by manipulating the synthesis parameters. For these dielectric mirrors or reflectors, titanium dioxide $\left(\mathrm{TiO}_{2}\right)$ and silicon dioxide $\left(\mathrm{SiO}_{2}\right)$ are the best chosen materials due to their high and low refractive indices respectively and therefore, such multilayers structures offer high refractive index contrast which is the primary need to possess the reflection band in the specified wavelength range [10]. The properties of films can be modulated by sol reactivity, viscosity, water alkoxide ratio, solution $\mathrm{pH}$, catalyst etc. [11-13]. Further, spin coating parameters such as spin speed and time including calcination temperature plays a vital role for the film deposition.

Sang Hun Nam et al. studied the growth mechanism of hydrophilic $\mathrm{TiO}_{2}$ thin films by changing the precursor temperatures. The preferred calcination temperature was $500^{\circ} \mathrm{C}$ whereas the process temperatures were maintained to $75^{\circ}$ and $60^{\circ} \mathrm{C}$ for the deposition. The film prepared at precursor temperature $60^{\circ} \mathrm{C}$ showed transmittance about $77 \%$ in the wavelength from $400-700 \mathrm{~nm}$ with the low contact angle due to super-hydrophilic nature of $\mathrm{TiO}_{2}$ surface. However, films deposited at precursor temperature below $50^{\circ} \mathrm{C}$ or greater than $75^{\circ} \mathrm{C}$ were not satisfactory [14]. S. Sali et al. synthesized the nanocrystalline $\mathrm{TiO}_{2}$ thin films on planar and textured quartz and silicon substrates by spray pulverization method. The aim of this study was to explore the anti-reflective properties prepared at different temperatures using XRD, FTIR, Raman and UV-Vis. The film deposited on the textured substrate showed the better properties with its $80 \%$ transmittance, $15-9 \mathrm{~nm}$ grains size, 3.28-3.38 eV band gap, and 2.19-2.39 refractive index. The coatings thicknesses and refractive indices could be controlled to exhibit optimal optical properties for the solar cells [15]. H. Sedrati et al. presented the structural and optical properties of $\mathrm{SiO}_{2} / \mathrm{TiO}_{2}$ alternating layers by sol-gel dip-coating process. The prepared multilayers were characterized for XRD, FTIR, SEM and UV-Vis spectroscopy. SEM analysis revealed the deposition of homogeneous layers of $\mathrm{SiO}_{2}$ and $\mathrm{TiO}_{2}$. By FTIR measurement, the vibration of Si-O-Ti bond was confirmed, however, the transmittance of the multilayer was found to be decreased from $4.58 \%$ to $0.55 \%$, as shown by UV-Vis spectroscopy study [16]. H. H. Nguyen et al. studied the effect of precursor concentration on $\mathrm{TiO}_{2}$ thin film nanostructure using plasma chemical vapor deposition (PCVD) system. They reported the granular 
morphology in the prepared sample with the low concentration of titanium tetra-isopropoxide (TTIP) and the columnar morphology with the increased TTIP concentration. SEM analysis showed the granular and columnar shapes with the particles size 20, 60 and $100 \mathrm{~nm}[17]$.

In this paper, we report the morphological and optical properties of the dielectric mirrors consisting of two and half $\mathrm{TiO}_{2} / \mathrm{SiO}_{2}$ bilayers using a simple and inexpensive chemical method. This study explores the effect of precursor concentrations upon the deposited multilayer structures. Section second describes the experimental approach and the results are discussed in section third. Finally, the work is summarized in section four.

\section{Experimental}

The as-procured chemicals, titanium isopropoxide (TTIP), tetraethyl orthosilicate (TEOS), ethanol $\left(\mathrm{C}_{2} \mathrm{H}_{5} \mathrm{OH}\right)$, deionized water (DI) and hydrochloric acid $(\mathrm{HCl})$ were used without any purification. Various sol-gel processes were carried out as described here. For the preparation of low-precursor based solutions of $\mathrm{TiO}_{2}$ and $\mathrm{SiO}_{2}, \mathrm{C}_{2} \mathrm{H}_{5} \mathrm{OH}: \mathrm{DI}$ : TTIP: $\mathrm{HCl}$ and $\mathrm{C}_{2} \mathrm{H}_{5} \mathrm{OH}: \mathrm{DI}: T E O S: \mathrm{HCl}$ in the molar ratios of 20:1:1:0.02 and 20:1:1:0.02 respectively were used. In a similar way, for the preparation of high-precursor based solutions of $\mathrm{TiO}_{2}$ and $\mathrm{SiO}_{2}$ the volume of TTIP and TEOS was increased to $1.5 \mathrm{ml}$. All the solutions were aged for $24 \mathrm{hr}$ and later spin coated on the glass substrates in the sequence $\mathrm{TiO}_{2} / \mathrm{SiO}_{2}$ films. Before the spin coating process, the glass substrates were sonicated in ethanol and rinsed with deionized water. The spin speed was maintained to 3000 RPM for $30 \mathrm{sec}$. After spin coating, each films were thermally treated over the period of $30 \mathrm{~min}$ to remove the volatile solvents. Finally, $\mathrm{TiO}_{2}$ films were calcined for $60 \mathrm{~min}$ at temperature $500^{\circ} \mathrm{C}$ while $300^{\circ} \mathrm{C}$ was maintained for the $\mathrm{SiO}_{2}$ films.

The prepared bilayers were characterized for phase identification using X-ray diffraction (Bruker D8 Advance), chemical bond analyses by Fourier transform infrared (FTIR) spectroscopy (Bruker Vertex 70) surface topography by atomic force microscopy (AFM: Nanoscope -NSE in contact mode), surface morphology by field-emission scanning electron microscopy (FESEM: ZIESS) and reflectance study by ultraviolet-visible (UV-vis) spectrophotometer with a specular reflectance attachment (UV1800 Shimadzu).

\section{Results and discussion}

The multilayer structures of $\left(\mathrm{TiO}_{2} / \mathrm{SiO}_{2}\right)_{2.5}$ bilayer prepared with low and high-precursor concentrations were studied for the investigation of phase identification. Fig. 1 depicts the XRD pattern of $\left(\mathrm{TiO}_{2} / \mathrm{SiO}_{2}\right)_{2.5}$ bilayer prepared with low and high precursor concentrations. The diffraction peaks were found corresponding to the pure anatase phase; however, a rutile peak was also observed for the sample prepared with high-precursor concentrations. The diffraction peaks were assigned to planes (101), (112), (200), (211) and (204) located at $2 \Theta=25^{\circ}, 38^{\circ}, 48^{\circ}, 55^{\circ}$ and $62^{\circ}$ respectively for both the cases. However, an additional peak located at $2 \Theta=27^{\circ}$ was also found corresponding to the presence of rutile phase. The XRD patterns of both the samples are well matched with JCPDS\#21-1272 and JCPDS\#21-1276 which corresponds to the anatase and rutile phases of $\mathrm{TiO}_{2}$. One can also notice the broadening of anatase $\mathrm{TiO}_{2}$ peak corresponding to the plane (101) in both the samples which is assumed to be associated with the amorphous nature of $\mathrm{SiO}_{2}$ layer beneath the top $\mathrm{TiO}_{2}$ layer [15].

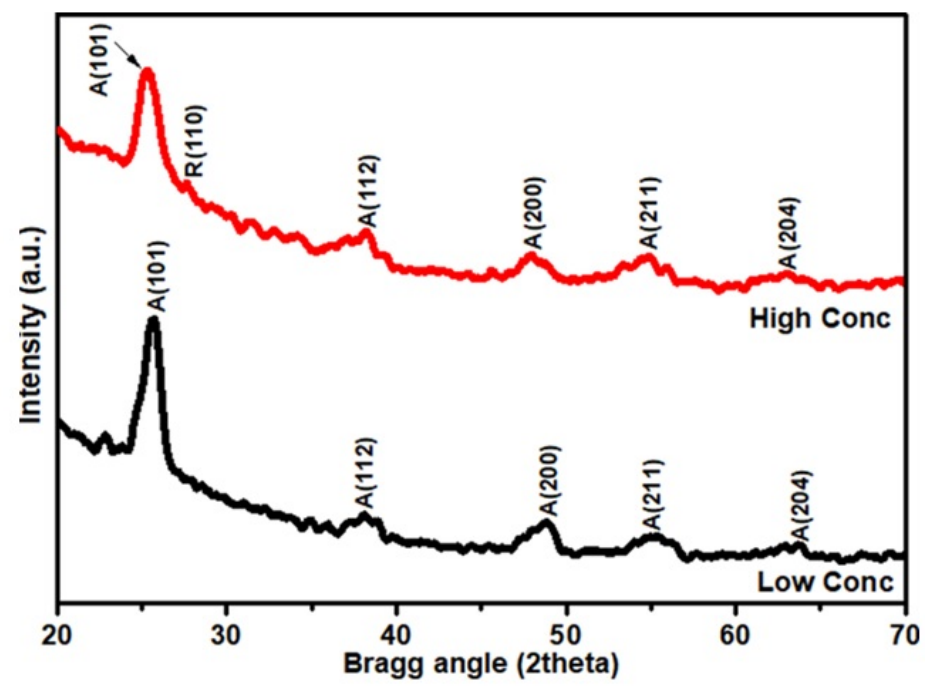

FIG. 1. XRD patterns of $\left(\mathrm{TiO}_{2} / \mathrm{SiO}_{2}\right)_{2.5}$ bilayer prepared with low and high-precursor concentrations 
Figure 2 depicts the FTIR spectra of $\left(\mathrm{TiO}_{2} / \mathrm{SiO}_{2}\right)_{2.5}$ bilayers prepared with the low and high- precursor concentrations of TTIP and TEOS respectively. The region from $600-900 \mathrm{~cm}^{-1}$ corresponds to the stretching vibrations of the Ti-O-Ti and Ti-O bonds.

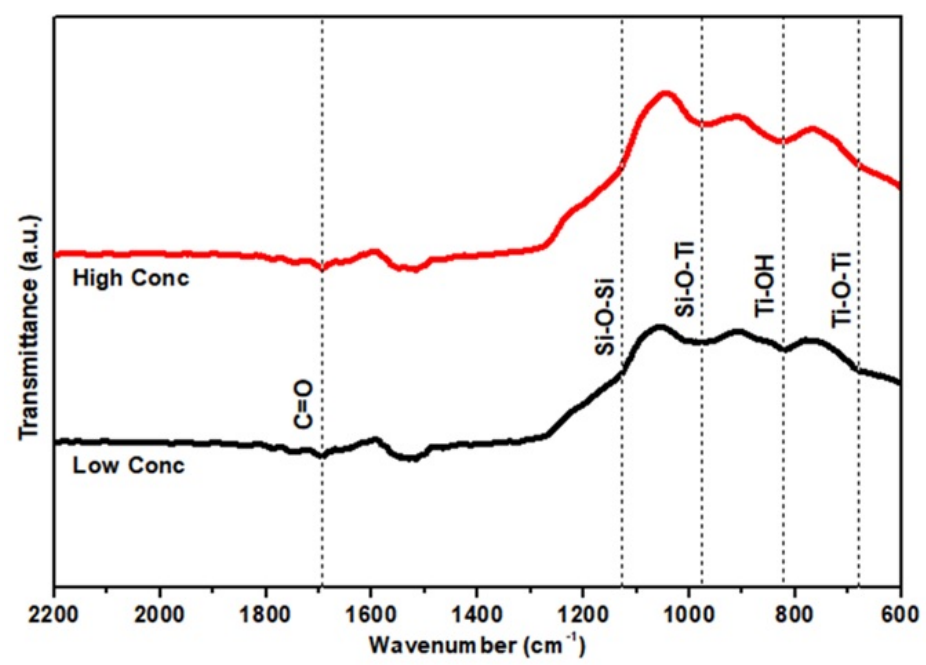

FIG. 2. FTIR spectra of $\left(\mathrm{TiO}_{2} / \mathrm{SiO}_{2}\right)_{2.5}$ bilayer prepared with low and high-precursor concentrations

We can observe a peak located at around $968 \mathrm{~cm}^{-1}$ which represents the vibration of Si-O-Ti bond. The peak corresponding to the stretching vibration mode of $\mathrm{Si}-\mathrm{O}-\mathrm{Si}$ is found located at $1128 \mathrm{~cm}^{-1}$. However, the peak originated at $1742 \mathrm{~cm}^{-1}$ is associated with the carbonyl bond $\mathrm{C}=\mathrm{O}$ which could be attributed to the non-hydrolytic sol-gel reaction of used acid and TTIP precursor. These vibration peaks coincide with the reported works $[15,16]$.The trend of the FTIR curves is almost identical the samples which were prepared with low and high- precursor concentrations.

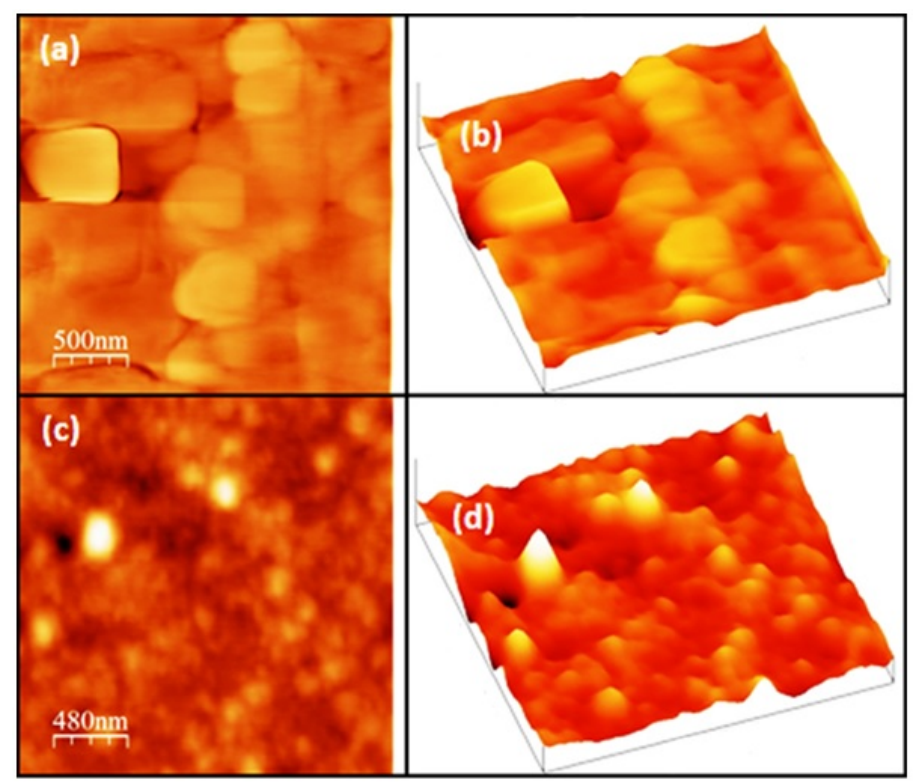

FIG. 3. AFM images of $\left(\mathrm{TiO}_{2} / \mathrm{SiO}_{2}\right)_{2.5}$ bilayer prepared with the high $(\mathrm{a}, \mathrm{b})$ and low-precursor $(\mathrm{c}, \mathrm{d})$ concentrations

To study the surface topography, we have performed the atomic force microscopy analysis of both the samples. Fig. 3 shows the AFM images of $\left(\mathrm{TiO}_{2} / \mathrm{SiO}_{2}\right)_{2.5}$ bilayers prepared with the low and high-precursor concentrations. Referring to Fig. 3(a and b), one can see the bigger grain size with their average size $362 \mathrm{~nm}$ corresponds to the sample prepared with high-TTIP concentration. But for the case of low-precursor concentration based sample, a decreased average grains size $104 \mathrm{~nm}$ can be noticed as depicted in Fig. 3(c and d). Similar, enhanced grains size 
with the increased precursor concentrations has been reported [16-18]. The high precursor concentration led to bigger crystallite size as a results increased grain size was observed. In addition, plate shape grains were also noticed which could be associated with the defects.

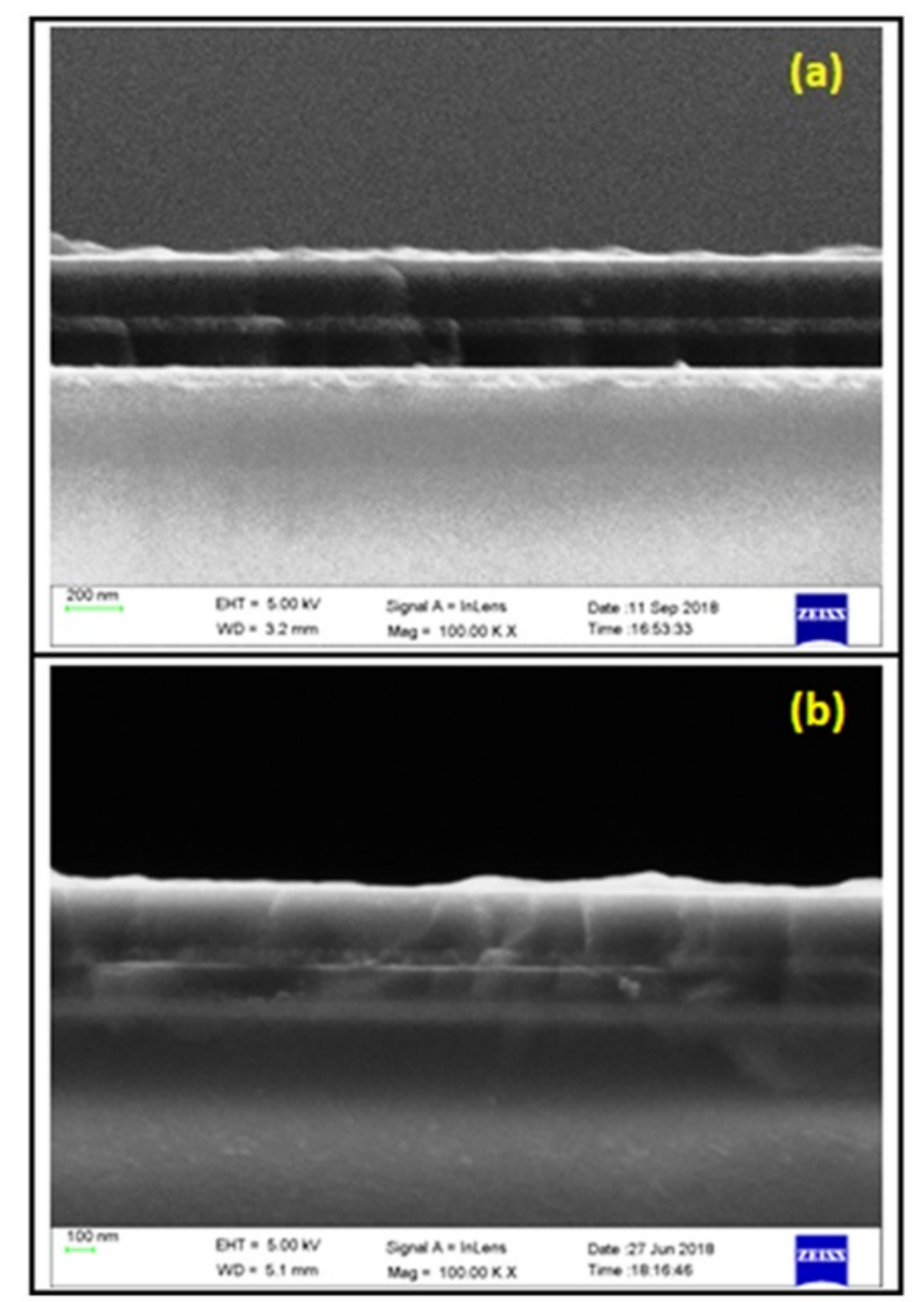

FIG. 4. Cross-section FESEM images of $\left(\mathrm{TiO}_{2} / \mathrm{SiO}_{2}\right)_{2.5}$ bilayer prepared with low (a) and high (b) precursor concentrations

One-dimensional periodic structure of $\mathrm{TiO}_{2} / \mathrm{SiO}_{2}$ films can be observed in Fig. 4. As depicted in Fig. 4(a), the low-precursor based sample shows the distinguished layers of $\mathrm{TiO}_{2}$ (brighter) and $\mathrm{SiO}_{2}$ (darker) films as compared to Fig. 4(b) which shows the disturbed interfaces of the top two films of $\mathrm{TiO}_{2}$ and $\mathrm{SiO}_{2}$. In addition, the enhanced precursor concentrations disclose the disturbed surface morphology as observable in Fig. 4(b). For the case of lowprecursors concentrations, the thicknesses of the $\mathrm{TiO}_{2}$ and $\mathrm{SiO}_{2}$ films (from bottom) were 51, 95, 68, 118 and $58 \mathrm{~nm}$ whereas $60,103,70,130$ and $67 \mathrm{~nm}$ respectively for the high-precursor concentrations based sample.

The prepared Bragg mirrors were studied for the reflectance from the range of ultra-violet to infrared wavelength as shown in Fig. 5. We can clearly observe the appearance of reflection windows (stop bands) from wavelength 552-958 nm and 545-1100 nm for the multilayer structures prepared with the low and high-precursor concentrations respectively. Both samples exhibit as much as $100 \%$ reflectance. As compared to previously reported works, visible reflectors consisting of 7 bilayers of $\mathrm{TiO}_{2} / \mathrm{SiO}_{2}$ were prepared by Anaya et al., Dubey et al. and Zhou et al. along with the 10 bilayer based structure reported by Dhruv et al, our samples show the better results only with 2.5 bilayers [19-22]. In addition, previously reported results were limited to their reflectance in visible wavelength region whereas our 2.5 bilayers based samples show the reflectance in the infrared region. In this way, our preparation of such multilayer reflectors reduces the efforts, time and the fabrication cost Remarkably, the reflection band for the case of the sample prepared at high-precursor concentrations shifted towards the further infrared wavelength. This shifting of 


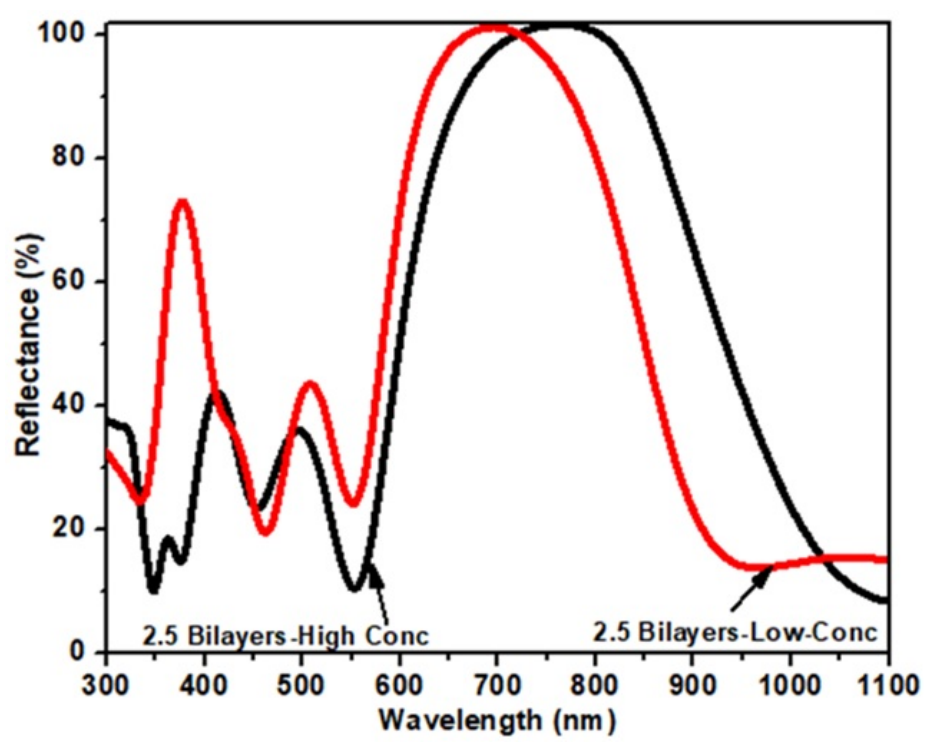

FIG. 5. Reflectance spectra of $\left(\mathrm{TiO}_{2} / \mathrm{SiO}_{2}\right)_{2.5}$ bilayer prepared with low and high-precursor concentrations

the reflection band is attributed to the increased grains size as observed in Fig. 3, due to which the thickness of the individual films were also increased as seen in Fig. 4. The center wavelengths of the Bragg mirrors prepared with low and high-precursor concentrations were found to be at 720 and $764 \mathrm{~nm}$ respectively.

\section{Conclusion}

Multilayer structures of $\left(\mathrm{TiO}_{2} / \mathrm{SiO}_{2}\right)_{2.5}$ bilayers fabricated by the sol-gel spin coating method have been studied. XRD measurement endorsed the dominant peaks of the anatase phase of $\mathrm{TiO}_{2}$. However, the broadening of predominant peak of the plane (101) was also noticed which could be associated with the amorphous nature of the $\mathrm{SiO}_{2}$ film fabricated beneath the top $\mathrm{TiO}_{2}$ film. FTIR investigation showed the corresponding vibration stretching peaks for the Ti-O-Ti, Si-O-Si and Ti-O-Si bonds. By AFM measurement, the estimated average grains size of the 5 layer- $\mathrm{TiO}_{2} / \mathrm{SiO}_{2}$ films were 104 and $362 \mathrm{~nm}$ for the samples prepared with low and high-precursor concentrations respectively. FESEM study endorsed the fabrication of five-alternate films of $\mathrm{TiO}_{2}$ and $\mathrm{SiO}_{2}$. The thicknesses of the individual films were observed to be increased as compared to films prepared with the low-precursor concentrations. This increment is attributed to the increased grains size as evidenced by the AFM measurement. The reflectance of both the samples is found to be satisfactory in terms of the Bragg mirrors from the visible-infrared wavelength region. The center wavelengths of the Bragg mirrors were 720 and $764 \mathrm{~nm}$ corresponding to the samples prepared with low and high-precursor concentrations respectively. With the increased precursor concentrations, the reflection band is observed to be shifted towards the near-infrared region. This shifting of reflection band is attributed to the increased grain size which is due to the high-precursor concentrations. Finally, the Bragg mirrors of $\left(\mathrm{TiO}_{2} / \mathrm{SiO}_{2}\right)_{2.5}$ bilayers fabricated by the simple process demonstrated the broad reflectance band in the visible-infrared wavelength range.

\section{Acknowledgements}

We acknowledge the financial support provided by the UGC-DAE CSR, Indore (India).

\section{References}

[1] Tikhonravov A.V. Some theoretical aspects of thin-film optics and their applications. Applied Optics, 1993, 32, P. 5417-5426.

[2] Schock H.W. Thin film photovoltaics. Applied Surface Science, 1996, 92, P. 606-616.

[3] Dubey R.S., Ganesan V. Visible and near-Infrared wavelength selective dielectric reflectors for light management Applications. Superlattices and Microstructures, 2018, 122, P. 228-234.

[4] Joannopoulos J.D., et al. Photonic crystals:molding the flow of light. Princeton University Press, Princeton, 2-nd edn, 2008.

[5] Chen K.M., Sparks A.W., Luan H.C., Lim D.R., Wada K., Kimerling L.C. $\mathrm{SiO}_{2} / \mathrm{TiO}_{2}$ omnidirectional reflector and microcavity resonator via the sol-gel method. Appl. Phys. Lett., 1999, 75, P. 3805-3808.

[6] Johnson D.C., Ballard I., Barnham K.W.J., Bishnell D.B., Connolly J.P., Lynch M.C., Tibbits T.N.D., Ekins-Daukes N.J., Mazzer M., Airey R., Hill G., Roberts J.S. Advances in Bragg stack quantum well solar cells. Sol. Energy Mater. Sol. Cells, 2005, 87, P. 169-179.

[7] Vossen J.L., Kern W. Thin Film Processes II. 1-st ed., Academic Press, San Diego, CA, 1991. 
[8] K.-Il Jang, Hong E., Kim J.H. Effect of an electrodeposited $\mathrm{TiO}_{2}$ blocking layer on efficiency improvement of dye-sensitized solar cell. Korean J. Chem. Eng., 2012, 29, P. 356-361.

[9] Chopra S., Sharma S., Goel T.C., Mendiratta R.G. Electrical and optical properties of sol-gel derived La modified PbTiO 3 thin films. Appl. Surf. Sci., 2004, 236, P. 321-327.

[10] Gracia F., Yubero F., Holgado J.P., Espinós J.P., González-Elipe A.R., Girardeau T. $\mathrm{SiO}_{2} / \mathrm{TiO}_{2}$ thin films with variable refractive index prepared by ion beam induced and plasma enhanced chemical vapor deposition. Thin Solid Films, 2006, 500, P. 19-26.

[11] Yang L.-L., Lai Y.-S., Chen J.S., Tsai P.H., Chen C.L., Chang C.J. Compositional tailored sol-gel $\mathrm{SiO}_{2}-\mathrm{TiO}_{2}$ thin films: Crystallization, chemical bonding configuration and optical properties. J. Mater. Res., 2005, 20, P. 3141-3149.

[12] Gauthier, Bourgeois S., Sibillot P., Maglione M., Sacilotti M. Growth and characterization of AP-MOCVD iron doped titanium dioxide thin films. Thin Solid Films, 1999, 340, P. 175-182.

[13] Sarah P., Saad M., Sutan H.B., Shariffudin S.S. TiO 2 thin film via sol-gel method: Investigation on molarity effect. IOP Conf. Ser. Mater Sci. Eng., 2015, 99, P. 12006.

[14] Sang-Hun Nam, Sang-Jin Cho and Jin-Hyo Boo. Growth behavior of titanium dioxide thin films at different precursor temperatures. Nanoscale Res. Lett., 2012, 7(89), P. 1-6.

[15] Sedrati A.H.,Bensaha R., Brahimi M., Dehdouh H., Bensouyad H., Abbas F., Toubal B. Correlation between structural and optical properties of $\mathrm{SiO}_{2} / \mathrm{TiO}_{2}$ multibilayers processed by sol-gel technique and applied to Bragg reflectors. Materials Science An Indian Journal, 2013, 9(3), P. 113-118.

[16] Sali S., Kermadi S., Zougar L., Benzaoui B., Saoula N., Mahdid K., Aitameur F., Boumaour M. Nanocrystalline properties of TiO 2 thin film deposited by ultrasonic spray pulverization as an anti-reflection coating for solar cells applications. J. Elect.Eng., 2017, 68, P. 24-30.

[17] Nguyen H.H., Kim D.-J., Park D.-W., Kim K.-S. Effect of initial precursor concentration on $\mathrm{TiO}_{2}$ thin film nanostructures prepared by PCVD system. Journal of Energy Chemistry, 2013, 22, P. 375-381.

[18] Lalchand A Patil, Dinesh N Suryawanshi, Idris G Pathan, Dhanashri G Patil. Effect of variation of precursor concentration on structural, microstructural, optical and gas sensing properties of nanocrystalline $\mathrm{TiO}_{2}$ thin films prepared by spray pyrolysis techniques. Bull. Mater. Sci., 2013, 36(7), P. 1153-1160.

[19] Miguel Anaya, Andrea Rubino, Mauricio E. Calvo and Hernan Miguez. Solution processed high refractive index contrast distributed Bragg reflectors. J. Mater. Chem. C, 2016, 4, P. 453-4537.

[20] Dubey R.S., Ganesan V. Fabrication and characterization of $\mathrm{TiO}_{2} / \mathrm{SiO}_{2}$ based Bragg reflectors for light trapping applications Results in Physics, 2017, 7, P. 2271-2276.

[21] Shengjun Zhou, Haohao Xu, Mengling Liu 1,2, Xingtong Liu, Jie Zhao, Ning Li and Sheng Liu, Effect of Dielectric Distributed Bragg Reflector on Electrical and Optical Properties of GaN-Based Flip-Chip Light-Emitting Diodes. Micromachines, 2018 , 9, P. 650.

[22] Dhruv Pratap Singh, Seung Hee Lee, Il Yong Choi, and Jong Kyu Kim. Spatially graded $\mathrm{TiO}_{2}-\mathrm{SiO}_{2} \mathrm{Bragg}_{\mathrm{g}}$ reflector with rainbow-colored photonic band gap. Optics Express, 2015, 23(13), P. 17568-17575. 